\title{
The Influence of Waiting Lines Management on Customer Satisfaction in Commercial Bank of Ethiopia
}

\author{
Alemu Zemene Desta \\ MBA, Department of Management, Adigrat University, Ethiopia \\ Tewedros Hiluf Belete \\ MBA, Department of Management, Adigrat University, Ethiopia
}

\begin{abstract}
The main objective of the study is to find out how queue management affects the level of customer satisfaction in the case of Commercial Bank of Ethiopia. The study tried to discover the impact of queue management in the Bank on the behavior of consumers the article is carried out in the following logical sequence: the nature and impact of queue management on customer satisfaction, evaluation of queue management mechanisms used, the key problems that face commercial Bank of Ethiopia in the implementation and administering of queue management. The methodological tools of the work include: the method of questioning (to collect primary information from both the client base and operational managers), descriptive statistics and STATA (for data analysis based on analytical statistical tools frequency distribution tables, cross-tabulation), regression model (to determine the influence of independent variables on the dependent value). Independent factors are presented by the author in the form of waiting environment, perception of waiting time, the information provided to the client from the commercial Bank and queue discipline, dependent indicator - the level of customer satisfaction. As a result of the study, the author concludes that the majority of clients of the commercial Bank of Ethiopia are not satisfied with the current mechanisms of the queue management. The paper states that the key factor influencing customer satisfaction is the waiting time. The study empirically confirms that the Bank's customers are not satisfied with the information that comes into the waiting room, and the conditions of waiting in banks. The author states the following reasons for dissatisfaction with the mechanisms of queue management on the part of customers: the use of a physical bank, manual queue measurement systems, poor-quality Internet banking, and mobile banking. The paper substantiates recommendations for Ethiopian commercial banks to increase their additional investment in queue management mechanisms, which will contribute to increasing customer satisfaction through the introduction of warning and alarm systems, the use of interactive communication, and advertising on television screens.
\end{abstract}

Keywords: Commercial Bank, Customer satisfaction, Queue management mechanisms

JEL Classification: H12, D12.

Cite as: Desta, Al. Z., Belete, T. H. (2019). The Influence of Waiting Lines Management on Customer Satisfaction in Commercial Bank of Ethiopia. Financial Markets, Institutions and Risks, 3(3), 5-12. http://doi.org/10.21272/fmir.3(3). 5-12.2019.

(C) The Authors, 2019. This article is published with open access at Sumy State University.

\section{Introduction}

The waiting line or queue management is a critical part of the service industry. It deals with the issue of treatment of customers in sense reduce waiting time and improvement of service. Queue management deals with cases where the customer arrival is random; therefore, service rendered to them is also random. A service organization can reduce cost and thus improve profitability by efficient queue management. A cost is associated with the customer waiting in line and there is a cost associated with adding new counters to reduce service time. Queue management looks to address this trade-off and offer solutions to management. Waiting is often an unavoidable experience in many business settings. At the hospital, petrol pumps, bus 
stop, or in the canteen, people wait for their turn so waiting in lines seems to be part of everyday life. People usually wait in line when the demand for a service exceeds its supply (Cavas, 2007).

Waiting in lines seems to be part of our everyday life: - at the hospital, filling station, bus stop, restaurant, supermarkets, and banks' or in the canteen. Queues form when the demand for a service exceeds its supply (Cavas, 2007). The unpleasant experience of waiting in line can often hurt on the rest of a customer's experience with a firm. How managers address the waiting line issue is critical to the long-term success of their firms (Davis et al, 2003).

\section{Customer Satisfaction as Function of Waiting Time}

In time-based competition, one of the main objectives of service companies is to minimize customer waiting. Waiting, however, can be defined in several ways. Different customer groups can have different average waiting times. Besides the mean, the standard deviation or the distribution of waiting times are also important characteristics of the waiting process. Moreover, the actual and perceived length of waits can also be differentiated.

Time can be considered as a resource. As such, a resource, like money, time can be gained and can be lost, that is, can be saved and can be wasted. In this

Pei-Chun et al., (2006) finding suggested that some bank should add more ATMs to reduce customer waiting time. Tian et al., (2011) examined the queuing system of the bank based on business process reengineering. Their findings showed that if the bank uses the simulating method to determine the number of open servers by referring to dynamic statistics; it will improve much in flexibility and make full use of the current resources.

\section{Need for the Study}

Studies on the relationship between waiting time and satisfaction are lacking in commercial bank of Ethiopia. As time becomes more precious compared to about 5 to 10 years ago, there is essential for an organization to properly deal with the management wait of 'customers' waiting' in the organization. The affluent and high standards of living further enhance Malaysian customers' search for value in services.

Waiting in line is common phenomena in daily life, for example, banks have customers in line to get service of a teller, cars queue up for re-filling, and workers line up to access machine to complete their job. Therefore, management needs to work on formula, which will reduce wait time and create delighted customers without incurring an additional cost. Generally, queue management problems are tradeoffs situation between costs of time spent in waiting with the cost of additional capacity or machinery.

Toshiba et al., (2013) finding showed that the efficiency of commercial banks is improved by the queuing number, the service stations number, and the optimal service rate. Therefore, conducting such research in the banking system of Ethiopia context may suggest effective and practical, and increasing customer satisfaction with relation to profit maximization in line with realizing the objective of measuring the behavioral queuing characteristics of customers in terms of their arrival and service rate, respectively in the banking system.

\section{Research Objectives}

The main objective of this research is to find out how waiting lines management influences customer satisfaction in Ethiopian commercial banks. Specifically, the objectives of this study are:

1. To identify the challenges that the bank faces in exercising waiting lines management

2. To determine how commercial bank of Ethiopia manages waiting lines

3. To determine the effect of waiting lines management on customer satisfaction 


\section{Significance of the Study}

This study would have great importance, whereby it will generally add up to the store of knowledge on the effect of waiting lines management with customer satisfaction in the banking industry.

This study can serve as a guideline for the formulation of policies on waiting line management and customer satisfaction in banks. By coming up with policies on how to manage customers waiting lines, banks will be in a position to achieve customer satisfaction. The study also can serve as strategies for banks in managing unavoidable waiting lines whereby at the end of this research, this study will come up with strategies of overcoming challenges experienced by banks while trying to manage waiting lines.

\section{Literature Review}

Literature available on waiting line management indicates that waiting in line or queue causes inconvenience to customers and economic costs to individuals and organizations. Hospitals, airline companies, banks, manufacturing firms, etc. try to minimize the cost involved in waiting and the cost of providing service to their customers. Therefore, the speed of service is very important and increasingly becoming a competitive parameter (Katz et al., 1991). Many studies have shown the negative effect of queues on consumers (Hui and Tse, 1996). As the perceived time of waiting increases, customers get dissatisfaction (Katz et al., 1991). First, in today's fast-moving lifetime has become more precious and valuable commodity especially in developed countries where the standards of living are very high. So, as a result people are less willing to wait for services. Second, this is a growing realization by organizations to make their customer satisfied and also to retain them to get business in today's competitive environment. Finally, advances in technology such as computers, the internet, etc. Nosekital., 2001) have provided firms with the ability to provide faster services. Addressing the problems of queuing involves a trade-off between the costs of customers waiting time and the cost of providing faster service. Katz et al. (1991) argued that we can control service waits by two techniques: the first one is operations management and the second one is perceptions management.

Davis and Vollman (1990) say that the number of time customers must spend waiting for services can significantly influence their satisfaction. Furthermore, Taylor, (1994) has demonstrated that customer satisfaction is not only affected by waiting time but also by customer expectations towards services or attribution of the causes for the waiting. Taylor et al. (1994) have observed that the perceived waiting time is usually different from the actual waiting time. A good flow of customers means that the customers queuing is minimized while poor customers flow means customers suffer considerable queuing delays (Hall, 2006). Queuing theory can be diversely applied and has been used mainly by the service industries (Nosek and Wilson, 2001). A queuing system or waiting lines consists of six major components: the population, the arrival, queue itself queue discipline, service mechanism, and departure or exit.

a) The population source serves as from where arrivals are generated. Arrivals of customers or students at the university may be drawn from either a finite or an infinite population. A finite population source usually refers to the limited size of the customer pool. Alternatively, an infinite source is unlimited.

b) The queue discipline is the sequence in which customers or students are processed or served. The most common and widely used discipline is first come, first served (FCFS). Other disciplines are last come, first served (LCFS) and service in random order (SIRO). Sometimes customers may also be selected from the queue based on some order of priority (Taha, 2005).

c) The service mechanism describes how the customer is served at the source. Nosek and Wilson (2001) conclude that the number of servers and the duration of the service time-both of which may vary time to time and also in a random fashion. The choices of facility structure can be determined by the number of lines and servers. The common service facility structures are single-channel, single-phase; single-channel, multiphase; multichannel, single-phase and multi-channel, multiphase.

d) The departure or exit occurs when a customer is served. Two possible exit scenarios are: 
(a) The customer may return to the source population and immediately become a competing candidate for service again;

(b) There may be a low probability of re-service.

\section{Research Methodology}

Research Design and Strategy. This study applied a cross-sectional survey since the data were collected at one point in time from the sample respondents to describe the total population. Concerning research strategies, the study was employed both qualitative and quantitative ones. Because the mixed method is considered as a tool to triangulate the result of single approach through multiple methods (Johnston, 2010). A quantitative method is selected because it is viewed as effective to gather large data and comprehensive issues at a specified time (Ngwenya, 2010). While the qualitative method is selected based on the assumption that it enables the researcher to generate meanings and phenomena within the real context of the research participants and to fill the gap left by the quantitative one (Kothari, 2004). Therefore, the mixed method was adopted to make the study more reliable through triangulation. The research was an empirical study carried out as a census survey of all the 3 commercial banks. Survey design is the best suited for these requirements because it will obtain an in-depth understanding on how commercial banks manage waiting lines, the challenges experienced by banks while managing waiting lines and determining the effects of customer waiting time on customer satisfaction. It also provided a comprehensive basis for analysis and gathering primary information specific to this survey.

\section{Data Types and Sources}

The study used primary data to get consolidated data to reach on concrete findings. The primary sources of data were collected from the customers of the bank and operational managers of the banks.

\section{Population}

The population of interest in this study comprised commercial banks of Ethiopia in Adigrat. The total number of commercial banks in the town is 3 . The respondents were both commercial banks customers and operations managers. Adigrat main branch, Meda Agame branch and Welwalo branch 33 560, 21,210 and 12,671 customers respectively except special customers. Customers targeted were the non-executive (special) customers since they mostly queue hence in a position to answer how satisfied they are with waiting lines management in banks. The reason why operations managers were chosen is that they know how the bank manages customers waiting lines and the challenges faced by the bank while managing customers waiting lines.

Moreover, Carvalho (1984) developed a method of sample size determination in the following manner.

Table 1. A method of sample size determination

\begin{tabular}{|c|c|c|c|}
\hline Population size & Small & Medium & Large \\
\hline $51-90$ & 5 & 13 & 20 \\
\hline $91-150$ & 8 & 20 & 32 \\
\hline $151-280$ & 13 & 32 & 80 \\
\hline $281-500$ & 20 & 50 & 125 \\
\hline $501-1200$ & 32 & 80 & 200 \\
\hline $1201-3200$ & 50 & $\mathbf{1 2 5}$ & 315 \\
\hline $3201-10,000$ & 80 & $\mathbf{2 0 0}$ & 500 \\
\hline $10,001-35,000$ & 125 & $\mathbf{3 1 5}$ & 500800 \\
\hline $35,001-150,000$ & 200 & 500 & \\
\hline
\end{tabular}

Source: Carvalho (1984).

\section{Sampling Methods}

After sample determination, the researcher distributed the questionnaire by using convenient sampling and purposive sampling for selecting operational manager of each branch. 


\section{Sample Size}

Based Carvalho (1984) sample population determination the samples was 315 Adigrat main branch 200 Meda Agame branch and 125 from Welwalo branch were taken.

\section{Data Collection Methods and Instrument}

Primary data was collected for this study where both customers and operations managers were involved. Self-administered questionnaires were given to both managers and customers. The questionnaire was semistructured; having both open-ended and closed-ended questions. The questionnaires were administered by the researcher to operations managers and customers of commercial banks. Likert scale was used.

\section{Data Analysis}

Data collected were tabulated, classified and coded. The STATA Version 14 used to extensively analyze the data using analytical statistics such as tables, frequency distributions, and cross-tabulations. Descriptive statistics, percentages and mean scores were used to describe the information of the respondents, how commercial banks manage waiting lines and challenges faced while managing the waiting lines. The regression model was also used to find out whether the independent variables predict the given dependent variable. That is, if waiting environment, perceived waiting time, and information provided and Queue discipline has an impact on customer satisfaction.

$\mathrm{y}=\mathrm{c}+\mathrm{P} 1 \mathrm{X} 1+\mathrm{P} 2 \mathrm{X} 2+\mathrm{P} 3 \mathrm{X} 3+\mathrm{P} 4 \mathrm{X} 4+\mathrm{P} 5 \mathrm{X} 5+\mathrm{e}$

$\mathrm{y}=$ Customer satisfaction with waiting lines management

$\mathrm{c}=$ Constant Term

$\mathrm{Pi}=$ Beta coefficients

$\mathrm{X} \mid=$ Perceived waiting time

$\mathrm{X} 2=$ Information provided

$\mathrm{X} 3=$ Waiting environment

X4= Queue discipline

$\mathrm{X} 5=$ challenges of waiting line management

$\mathrm{e}=$ the standard error

\section{Results and Discussion}

The purpose of this study was to see the influence of Queue lines Management on customer satisfaction in Commercial Bank of Ethiopia Branches in Adigrat. The study used observation, and questionnaire for research purpose and, to analyze the researcher has used the survey research methods because the respondents are more than 640 individuals and this kind of research is mainly associated with descriptive and causal research situations.

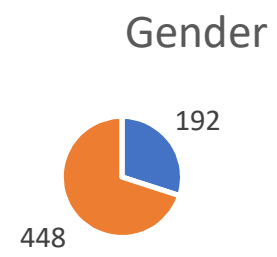

$$
\begin{aligned}
& \text { - Femal } \\
& \text { - Male } \\
& \text { - }
\end{aligned}
$$

Figure 1. Gender 
As shown above the total respondents $448(70 \%)$ are males and 192(30\%) are females and more than $416(65 \%)$ of the respondents has got a diploma. $531(83 \%)$ of the respondents are customers of the bank for more than two years. From the total respondents $608(95 \%$ or all most all respondents face a Queue when they enter those Branches hall. And 493(77\%) of the respondents express their dissatisfactions towards Queue interruption. And, the customers are dismayed because of the server's behavior towards serving customers without their turn. Out of the total respondents, 563(88\%) of the respondents believes number servers are not enough to serve the existing customers. Concerning, customers need while in the Queue $378(59 \%)$ of the respondents need comfortable waiting environment, $83(13 \%)$ of the respondents needs indication of waiting time, $51(8 \%)$ of the respondents needs entertaining things while waiting in the Queue and $128(20 \%)$ of the respondents needs fairness of Queuing System. When we see respondents view on the serving capacity of the servers $499(78 \%)$ of respondents are not satisfied with the serving capacity of server's special speeds of the tellers. Queuing model can be analyzed based on mathematically and data was taken from three branches average and the average waiting time of the branches is 12 minutes, so it is somewhat long regarding the sensitivity of the banking industry. Finally, when we see respondents view on Expansion of waiting lines management System in other branches $467(73 \%)$ respondents are happy to see the system in other banks.

Table 2. Regression output

\begin{tabular}{|l|l|l|l|l|l|l|}
\hline Model & \multicolumn{3}{|c|}{ Unstandardized } & \multicolumn{3}{l|}{ Standardized Coefficients } \\
\hline & & B & Std. Error & Beta & $t$ & Sig. \\
\hline 1 & Constant & 1444.434 & 3680.374 & & .392 & .715 \\
& & & & & & \\
\hline & Perceived waiting time & .982 & .049 & 1.012 & 19.904 & .000 \\
\hline & Information provided & 39.806 & 10.049 & .143 & 3.961 & .017 \\
\hline & Waiting environment & -2.032 & .480 & -.122 & -4.232 & .013 \\
\hline & Queue discipline & 5.991 & 23.805 & .030 & .252 & .814 \\
\hline & Challenges of waiting $m g t$ & -.910 & .931 & -.099 & -.977 & .384 \\
\hline$a$. & Dependent Variable: customer satisfaction \\
\hline
\end{tabular}

Based on the nonstandard coefficients we obtain the regression equation:

$y=1444.434+0.982 \times 1+39.806 \times 2-2.032 \times 3+5.991 \times 4-0.910 \times 5$

Where $\mathrm{x} 1=$ Perceived waiting time, $\mathrm{x} 2=$ Information provided, $\mathrm{x} 3=$ Waiting environment, $\mathrm{x} 4=$ Queue discipline $\mathrm{x} 5=$ Challenges of waiting $\mathrm{mgt}$.

Table 3. Estimation of the standard deviation - Model Summary

\begin{tabular}{|l|l|l|l|l|}
\hline Model & R & R Square & Adjusted R Square & Std. Error of the Estimate \\
\hline 1 & $.999^{\mathrm{a}}$ & .998 & .996 & 2168.975 \\
\hline
\end{tabular}

a. Predictors: (Constant), Queue discipline, Challenges waiting mgt, Information provided, Waiting environment, Perceived waiting time.

Source: completed by author.

The coefficient of determination $\mathrm{R}^{2}$ indicating the percent of how much of the total variance is explained by the independent variable is $99.80 \%$. The analysis of variance for multiple regression will be made starting from the following results.

Table 4. The analysis of variance for multiple regression

\begin{tabular}{|l|l|l|l|l|l|l|}
\hline Model & - & Sum of Squares & df & Mean Square & f & sig \\
\hline \multirow{4}{*}{1} & Regression & $1.087 \mathrm{E} 10$ & 5 & $2.174 \mathrm{E} 9$ & 462.098 & \multirow{2}{*}{$.000^{\mathrm{a}}$} \\
\cline { 2 - 5 } & Residual & 18817814.997 & 4 & 4704453.749 & & \\
\cline { 2 - 5 } & Total & $1.089 \mathrm{E} 10$ & 9 & & \\
\end{tabular}

a. Predictors: (Constant), Queue discipline, Challenges waiting mgt, Information provided, Waiting environment, Perceived waiting time.

b. Dependent Variable: customer satisfaction.

Source: completed by author.

10 


\section{Conclusion and Recommendations}

All most all (95\%) of the respondents say that whenever they arrive at the Bank there is Queue in the Branches whole. That is a reason for the customer's dissatisfaction on the Bank. $88 \%$ of the respondents believe a number of servers is not enough for serving the existing large number of customers. So, as much as possible the Bank should increase the number of server's by double to avoid concentration of customer in Branches whole. $88 \%$ of the respondents are dissatisfied on server's performance and the Bank should give enough on the job and off the job training to enhance the performance of the Server on customer handling and improve their skills. (59\%) of the respondents needs comfortable waiting environment and $51(8 \%)$ of the respondents needs entertaining things while waiting in the Queue and $128(20 \%)$ of the respondents needs fairness of Queuing System. That's why most of the respondent expresses their dissatisfaction over Queue interruption and the other part of the respondents needs an indication of waiting time. Accordingly, the bank ought to arrange comfortable chairs, internet, and televisions by which the bank can retain the customer's attention until their service time. The bank should provide direction in terms of dedicated terminals in self-service or receptionist to allow customers to take their place in the queue for service and communication to adjust waiting time according to the importance of the service to be provided.

Regarding Queue interruption (77\%) of the respondents express their dissatisfactions over server's who serving customers without queue number or their turn. And the Bank should control servers with such unprofessional manner by opening a new window for special customers such system has benefits for the Branch and the center on controlling purpose. All those branch managers give us the same response that the system forwards a report for the management which contains a number of customers served in each server (windows).

The study further recommends that lines management in the banks can be enhanced by implementing measures that will enhance customer flow management and an increase in the number of bank branches. The banks should also increase the number of terminals where deposits are made and emphasize on agency banking implementation.

The Bank could provide salary payments in Customers mother Company to minimize the length of Queue in the Branches whole and campaign for e-banking service users because the main reason for longing for Queue is salaries paid to customers. Bank can handle the largest number of customers out of the Branches whole and those ATMs could be available for service whenever needed. And the servers could be aware of what customer means and they should accept the principle of CUSTOMER IS A KING.

Might not be related to the study but network problem and shortage of cash for huge payment creates dissatisfaction on customers. As much as possible those branches should differentiate its customers based on their contribution to the Bank. Especially, customers who have high contributions on Deposit mobilization and foreign currency earnings for the Bank. The managers can use the results in process mapping and improvement areas to improve their customers' satisfaction by limiting waiting time. As service capacity increases, there is a reduction in the number of customers in the line and in their waiting times, which decreases queuing cost.

\section{References}

1. Davis, M. M., Aquila, J. N., Chase, B. R. (2003). Fundamentals of Operations Management. Boston: McGraw- Hill Irwin, Fourth Edition.

2. Davis MM, Vollmann T.E. (1990). A framework for relating waiting time and customer satisfaction in a service operation. J. Serv. Market, 4(1), 61-69.

3. Hui, M.K. and Tse, D.K. (1996). What to tell customers in waits of different lengths: an integrated model of service evaluations, Journal of Marketing, 60(2), 81-90.

4. Kandemir-Caues C, Cauas L (2007). An Application of Queuing Theory to the Relationship between Insulin Level and Number of Insulin Receptors. Turkish J. Biochem, 32(1), 32-38. 
5. Kasum, A. S., Abdulraheem, A., \&Olaniyi, T.A. (2006). Queue Efficiency in Nigeria Banks: A Comparative Analysis of Old and New Generation Banks. Ilorin Journal of Sociology, 2(1), 162-172. ISSN II7-9448I. 2.

6. Katz, K.L., Larson, B.M. and Larson, R.C. (1991). Prescription for Waitingin-Line Blues: Entertain, Enlighten, and Engage, Sloan Management Review, (32)2, 44-53.

7. Nosek AR, Wislon PJ (2001). Queuing Theory and Customer Satisfaction: A Review of Terminology, Trends and Applications to Pharmacy Practice. Hosp. Pharm, 36(3), 275-279.

8. Pei-Chun, L., \& Ann, S.Y. (2006). Service efficiency evaluation of automatic teller machines- a study of Taiwan financial institutions with the application of queuing theory. Journal of Statistics and Management Systems, 9(3), 555-570. 3.

9. Taha AH (2005). Operation Research: An Introduction. Delhi: Pearson Education, Inc., Seventh Edition.

10. Taylor, S. (1994). Waiting for service: The relationship between delays and evaluations of service. Journal of Marketing, 58(2), 56-70.

11. Tian, H., \& Tong, Y. (2011). Study on Queuing System Optimization of Bank Based on BPR. 3rd International Conference on Environmental Science and Information application Technology (ESIAT), 640-649. 4.

12. Toshiba, S., Sanjay, S., \& Anil, K.K. (2013). Application of Queuing Theory for the Improvement of Bank Service. International Journal of Advanced Computational Engineering and Networking, 1(4), 15-18. ISSN 2320-2106. 